\title{
Successful Treatment of Severe Falciparum Malaria With Adjunctive Use of Exchange Transfusion
}

\author{
Naif AlJohani MD', lan Davis MD² \\ 'Department of Medicine, QEII Health Science Center \\ ${ }^{2}$ Division of Infectious Diseases, QEII Health Science Center
}

\begin{abstract}
Although malaria is no longer endemic in Canada, it remains an important imported disease, principally among immigrants and travellers. The role of exchange transfusion in malaria treatment, in addition to standard anti-malarial treatment, remains controversial and is not well established. We report a case of severe malaria in a male traveller, complicated by multiorgan failure, septic shock, myositis, and unusual Streptococcus pneumoniae bacteremia. Manual exchange transfusion was used, in addition to artesunate-based therapy, and the patient responded well. This report shows that malaria remains an important differential diagnosis for travellers returning with fever and emphasizes the importance of prompt diagnosis and appropriate treatment.
\end{abstract}

\section{Case Presentation}

A frequent traveller to malaria-endemic areas, a 50-yearold Canadian, without a significant medical history, returned from a 4-week trip to Nigeria. His malaria chemoprophylaxis was stopped prematurely due to side effects. During the trip, he adopted appropriate measures to prevent mosquito bites and was up-todate on his vaccinations. Four days after returning to Canada, he became ill; his symptoms included fever, chills, sweating, headache, and joint pains, followed by diarrhea, jaundice, shortness of breath, and a noticeable darkening of urine.

He presented to a local hospital's emergency department where malaria was suspected; thin/thick blood smears confirmed an infection by Plasmodium falciparum. The parasitemia level was markedly high at $26 \%$. Upon admission, he was in respiratory distress; his temperature was $38{ }^{\circ} \mathrm{C}$, heart rate 118 beats/minute, blood pressure $110 / 70 \mathrm{~mm} \mathrm{Hg}$, respiratory rate 28 / minute, and oxygen saturation level $94 \%$, using a $40 \%$ FIO2 face mask. The patient's physical examination revealed icterus, fine bilateral inspiratory crackles, tachycardia, and mild tender hepatomegaly. Figure 1 shows two peripheral blood smears taken from the patient which demonstrate red blood cells heavily infected with malaria parasites.

The time between confirmation of his malaria diagnosis and the start of malaria treatment was approximately 1 hour. The patient's complete blood count showed a leukocyte count of $7.4 \times 10^{9} / \mathrm{L}(4.5-11.0)$, a hemoglobin level of $154 \mathrm{~g} / \mathrm{L}(120-160)$ and a platelet count of $12 \times 10^{9} / \mathrm{L}(150-350)$. His urea was $10 \mathrm{mmol} / \mathrm{L}$ (2.9-9.3) and creatinine $186 \mu \mathrm{mol} / \mathrm{L}$ (37-96). A liver test revealed the following: alanine aminotransferase $131 \mathrm{U} / \mathrm{L}$ (14-54), aspartate aminotransferase $165 \mathrm{U} / \mathrm{L}$ (15-41), lactate dehydrogenase $548 \mathrm{U} / \mathrm{L}$ (98-193), total bilirubin $130 \mu \mathrm{mol} / \mathrm{L}$ (0-16), and alkaline phosphatase 105 $\mathrm{U} / \mathrm{L}$ (32-92), his creatine kinase peaked at $2103 \mathrm{U} / \mathrm{L}$ (10-35U/L). The findings of an initial chest $\mathrm{x}$-ray were normal.

The patient's condition deteriorated rapidly in the emergency department, prior to admission to the critical care unit, where he was intubated, sedated, mechanically ventilated, and started on intravenous artesunate $(2.4 \mathrm{mg} / \mathrm{kg})$. A repeat chest $\mathrm{x}$-ray revealed signs of acute respiratory distress syndrome (ARDS). Artesunate was re-administered at 12, 24, and 48 hours after the first dose.

His hemoglobin levels dropped to $60 \mathrm{~g} / \mathrm{L}$, and his platelet count remained very low $\left(12 \times 10^{3} / \mu \mathrm{L}\right)$, necessitating multiple blood and platelet transfusions. A manual exchange transfusion (ET) was done within the first 24 hours, replacing $3000 \mathrm{~mL}$ of blood with $3517 \mathrm{~mL}$; the duration of the ET was 8 hours.

His renal function worsened, resulting in acute kidney failure, which required urgent hemodialysis. The patient's blood cultures were positive for Streptococcus pneumoniae and methicillin-sensitive Staphylococcus aureus. He was started on ceftriaxone (1 g intravenously daily), which was stepped down to amoxicillin/ clavulanic acid, based on culture sensitivities. 


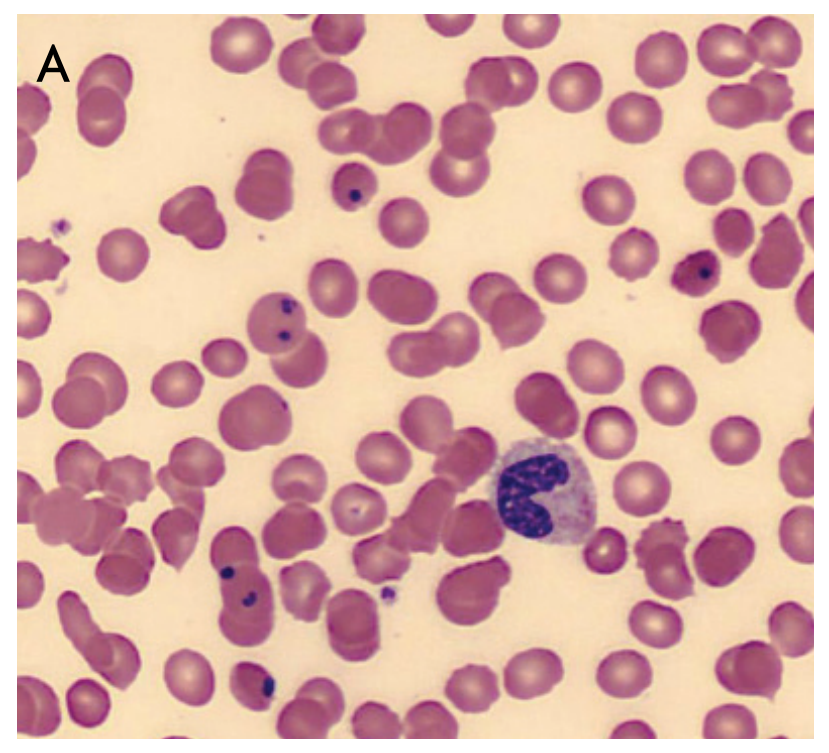

Figure 1. Malaria peripheral blood smears.

Repeated blood smears showed a dramatic decrease (to 5\%) in his parasitemia level after 36 hours and to $1 \%$ after 72 hours of treatment. After artesunate therapy was completed, oral atovaquone and proguanil (Malarone) was administered (4 tablets/day) for an additional 4 days. The patient was sent home in stable condition after 2 weeks of hospitalization. However, he required intermittent dialysis over the following 6 weeks until his renal function recovered.

\section{Discussion}

Malaria is endemic in most tropical countries. ${ }^{1,2}$ The World Health Organization (WHO) estimated that the number of cases of malaria increased from 233 million in 2000 to 244 million in 2005, but decreased to 225 million in 2009. ${ }^{3}$ Concurrently, the number of deaths due to malaria is estimated to have decreased from 985,000 in 2001 to 781,000 in $2009,{ }^{3}$ with most deaths being caused by P. falciparum infection. It is estimated that each year 1 million Canadians travel to areas where they may be at risk of contracting malaria, resulting in 350 to 1000 cases. ${ }^{4}$ In 2004, MacLean et al. published a detailed survey about the incidence of this disease in Canada. ${ }^{5}$ They reported that the majority of $P$. falciparum cases imported into Canada were acquired in sub-Saharan Africa, whereas the majority of $P$. vivax cases were acquired on the Indian subcontinent. ${ }^{4}$ In 1997, 2 cases of fatal falciparum malaria were reported in Canadians. ${ }^{6}$ An additional 7 falciparum malaria deaths were reported to have occurred between 1997 and 1999 in Canada or in Canadian travellers. ${ }^{7}$ From June 2001 to March 2007, there were 88 cases (33\% were children) of severe or complicated malaria reported in Canada, a mean of 14 cases per year. ${ }^{4}$ The incidence of

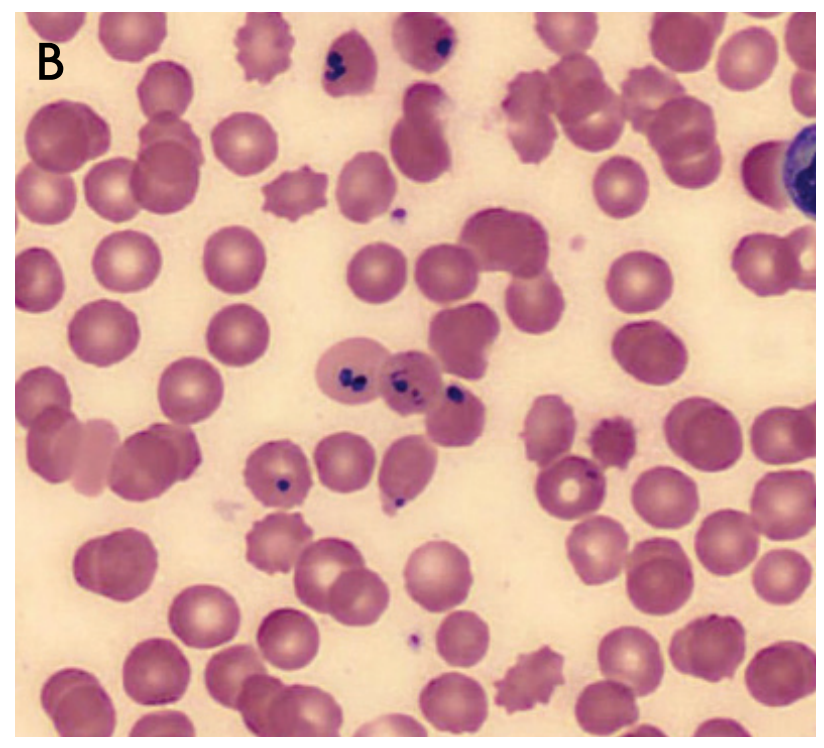

malaria and its related deaths in Canada are shown in Table $1 .^{8}$

Severe malaria is an acute disease, caused almost exclusively by $P$. falciparum, with major signs of organ dysfunction and/or high levels of parasitemia (>10\%) in blood smear, as described by WHO.,9,10

The symptoms of malaria may develop as early as 7 to 8 days after initial exposure, or may be delayed for months to years. The P.falciparum infection can rapidly become lethal, with multiple organ failure and can lead to death. In children, hypoglycemia, convulsions, and severe anemia are fairly common; acute renal failure and pulmonary edema are more common among adults, whereas, cerebral malaria with coma, shock, and acidosis can occur in both age groups, with increased morbidity and mortality rates. ${ }^{11}$ Progression of malaria from no symptoms to severe and complicated malaria can be extremely rapid, with death occurring within 36 to 48 hours. The diagnosis of malaria is often difficult in absence of specific symptoms of malaria, but an accurate diagnosis can be confirmed by demonstration of malaria parasite in the blood smear.

The malaria infection presents with a broad array of clinical presentations, such as; fever, chills, rigor, sweat, headache, nausea, vomiting, diarrhea, abdominal pain, malaise, muscle ache, joint pain, tiredness, and may be associated with severe breathing difficulties, low blood sugar, severe anaemia and jaundice. In more severe cases it may include seizures, coma, kidney and respiratory failure, and shock which may lead to death. 
Malaria in Canada is the most common specific diagnosis for a fever in a returned traveller. ${ }^{35}$ Other common infections include acute travellers' diarrhea, respiratory tract infection, Dengue Fever and enteric fever. All other possible diagnoses need to be excluded when fever begins within few days (7-8 days) after return from malaria endemic area, but can be reliably excluded if symptoms do not appear until $>2$ weeks. ${ }^{35}$

Management of patients with severe malaria presents a broad array of clinical challenges, given the complex pathophysiology of the infection and the involvement of multiple organ systems. ${ }^{1,12,13}$ These challenges are magnified by the emerging resistance of malaria to available treatment options. ${ }^{14}$ Artemisinin-based therapy is now the recommended first line of therapy for treatment of adults with severe falciparum malaria, in areas where intravenous artesunate is available. ${ }^{15-17}$ This recommendation is based on multiple, well-designed, randomized clinical trials that were conducted globally and on a recent Cochrane meta-analysis. ${ }^{17-19}$

ET has been proposed as an adjunctive anti-malarial treatment to remove infected red blood cells from circulation, thereby lowering the parasite burden. ${ }^{20,21}$ Other mechanisms may involve the removal of toxic substances, reducing microcirculatory sludging, and increasing the oxygen-carrying capacity of the blood. ${ }^{22}$ WHO, however, suggested that the lack of consensus on the indications, benefits, dangers, and practical details of the procedure make it impossible to reach any conclusions regarding the use of this procedure. ${ }^{3}$

An English language literature review, conducted using the PubMed and Embase databases, from their inception through 2012, identified that use of ET was first reported in 1974 as a therapeutic adjunct for severe malaria. Although the efficacy of this procedure has not been established by randomized controlled trials, its benefits have allowed the rationale of use of ET in severe and complicated malaria. ${ }^{23}$ Many case reports, case series, and retrospective studies have reported about the successful use of ET in severe malaria. The meta-analysis concluded that "exchange transfusion does not appear to increase the survival rate"; however, authors concluded that the reviewed articles had significant problems with their comparability of the treatment groups, including the lack of a standardized assessments system. ${ }^{24}$ While there are numerous publications on the matter, they are all of small sample size and of lower overall quality. Moreover, there are no evidence-based guidelines on the use of ET in patients with severe malaria. ${ }^{21,24-32}$
Table 1. Incidence of malaria and death due to malaria in Canada

\begin{tabular}{lll}
\hline Year & $\begin{array}{l}\text { Recorded } \\
\text { Cases }\end{array}$ & $\begin{array}{l}\text { Deaths Due } \\
\text { to Malaria }\end{array}$ \\
\hline 1989 & 284 & - \\
1990 & 417 & - \\
1991 & 674 & - \\
1992 & 422 & - \\
1993 & 504 & - \\
1994 & 446 & - \\
1995 & 665 & - \\
1996 & 1018 & - \\
1997 & 1058 & - \\
1998 & 387 & - \\
1999 & 390 & - \\
2000 & 462 & 1 \\
2001 & 445 & 2 \\
2002 & 366 & 0 \\
2003 & 370 & 0 \\
2004 & - & 0 \\
2005 & - & 3 \\
2006 & - & 0 \\
2007 & - & 2 \\
2008 & - & \\
\hline & & \\
\hline
\end{tabular}

There are some questions regarding how to perform ET appropriately. ${ }^{3}$ The two methods used are the traditional manual ET approach and automated erythrocytapheresis. Manual ET was primarily used before 2000; the procedure is relatively time-consuming and may be associated with hemodynamic disturbances, which limit its use and may be a principal cause of the disagreements regarding the benefits and risks of the technique. Automated erythrocytapheresis has significant advantages over manual ET in terms of speed, efficiency, hemodynamic stability, and retention of plasma components, and may represent an improvement in adjunctive therapy for severe malaria. ${ }^{33}$ The other technical issue is the amount of blood that should be removed or exchanged. One author concluded that the volume of a patient's blood involved in ET should be 2,000 $\mathrm{mL}$ for an average parasitemia of $10 \%, 4,000 \mathrm{~mL}$ for parasitemia of $>20 \%$, and 2,000 $4,000 \mathrm{~mL}$ for parasitemia of $10-20 \%{ }^{34}$ Those results were confirmed and detailed in other studies. ${ }^{31,32}$ 
In summary, Canadian physicians need to remain alert to the possible diagnosis of malaria in patients who may have recently travelled to areas where malaria is endemic. In cases of severe malaria, ET, especially if automated, may be considered as an adjunctive treatment to standard anti-malarial treatment. If automated erythrocytapheresis is not available, manual ET maybe performed, but only in an intensive care unit setting with close monitoring of patient hemodynamics.

\section{References}

1. Kampfl AW, Birbamer GG, Pfausler BE, Haring HP, Schmutzhard E. Isolated pontine lesion in algid cerebral malaria: clinical features, management, and magnetic resonance imaging findings. Am J Trop Med Hyg 1993;48:818-822.

2. World Health Organization. Communicable diseases cluster. Severe falciparum malaria. Trans $\mathrm{R}$ Soc Trop Med Hyg 2000;94(Supplement 1):1-90.

3. WHO. World Malaria Report 2010. http://www.who.int/malaria/ world_malaria_report_2010/worldmalariare port2010.pdf

4. Canadian Recommendations for the Prevention and Treatment of Malaria Among International Travellers - 2009. http:// www.phac-aspc.gc.ca/publicat/ccdr-rmtc/09vol35/35s1/ index-eng.php

5. MacLean, J. Malaria Epidemics and Surveillance Systems in Canada. Emerging Infectious Diseases; 2004. CDC.

6. Humar A, Sharma S, Zoutman D, Kain KC. Fatal falciparum malaria in Canadian travellers. CMAJ 1997;156:1165-1167.

7. Kain KC, MacPherson DW, Kelton T, Keystone JS, Mendelson J, MacLean JD. Malaria deaths in visitors to Canada and in Canadian travellers: a case series. CMAJ. 2001;164:654-659.

8. Deaths, by cause, Chapter I: Certain infectious and parasitic diseases (A00 to B99), age group and sex, Canada http://www5. statcan.gc.ca/cansim/a05?lang=eng\&id $=1020521 \&$ pattern $=102$ $0521 \&$ searchtypebyvalue $=1 \& \mathrm{p} 2=35$

9. Asiedu DK, Sherman CB. Adult respiratory distress syndrome complicating Plasmodium falciparum malaria. Heart Lung 2000;29:294-297.

10. Glikman D, Nguyen-Dinh P, Roberts JM, Montgomery CP, Daum RS, Marcinak JF. Clinical malaria and sickle cell disease among multiple family members in Chicago, Illinois. Pediatrics. 2007;120:e745-748.

11. White NJ, Breman JG. Malaria and babesiosis. In: Braunwald E, Fauci AS, Isselbacher KJ, et al, eds. Harrison's Online. New York, NY: McGraw-Hill; 2004;210.

12. Beg MA, Khan R, Baig SM, Gulzar Z, Hussain R, Smego RA Jr. Cerebral involvement in benign tertian malaria. Am J Trop Med Hyg. 2002;67:230-232.

13. Grace D, Lavery GG, Jackson P, Canavan DA, Fee JP. Intensive care management of multiple-organ dysfunction due to falciparum malaria in a married couple. Anaesthesia. 1994;49:686-690.

14. Taylor TE. Treatment of severe falciparum malaria; 2012 http://www.scribd.com/doc/79096365/Treatment-of-SevereFalciparum- Malaria

15. Maude RJ, Plewes K, Faiz MA, Hanson J, Charunwatthana P, Lee SJ, Tärning J, Yunus, EB, Hoque MG, Hasan MU, Hossain A, Lindegardh N, Day NP, White NJ, Dondorp AM. Does artesunate prolong the electrocardiograph QT interval in patients with severe malaria? Am J Trop Med Hyg 2009;80:126-132.

16. Poespoprodjo JR, Hasanuddin A, Fobia W, Sugiarto P, Kenangalem E, Lampah DA, Tjitra E, Price RN, Anstey NM. Severe congenital malaria acquired in utero. Am J Trop Med Hyg 2010;82:563-565.
17. Sinclair D, Donegan S, Lalloo DG. Artesunate versus quinine in the treatment of severe falciparum malaria in African children (AQUAMAT): an open-label, randomised trial. Cochrane Database of Systematic Reviews 2011;9.

18. Dondorp A, Nosten F, Stepniewska K, Day N, White N, South East Asian Quinine Artesunate Malaria Trial (SEAQUAMAT) group. Artesunate versus quinine for treatment of severe falciparum malaria: a randomised trial. Lancet 2005;366(9487):717-725.

19. Sinclair D, Donegan S, Lalloo DG. Artesunate reduces death from severe malaria. Cochrane Database of Systematic Reviews 2012;6.

20. Shelat SG, Lott JP, Braga MS. Considerations on the use of adjunct red blood cell exchange transfusion in the treatment of severe Plasmodium falciparum malaria; 2010. Transfusion. 2010;50:875-880.

21. Beards SC, Joynt SC, Joynt GM, Lipman J. Haemodynamic and oxygen transport response during exchange transfusion for severe falciparum malaria. Postgrad Med J 1994;70:801-804.

22. Phillips P, Nantel S, Benny WB. Exchange transfusion as an adjunct to the treatment of severe falciparum malaria: case report and review. Rev Infect Dis 1990;12:1100-1108.

23. Riddle M, Jackson JL, Sanders JW, and Blazes DL. Exchange transfusions as an adjunct therapy in severe plasmodium falciparum malaria: a meta analysis. Clin Infect Dis 2001;34:1192-1198.

24. Wong RD, Murthy AR, Mathisen GE, Glover N, Thornton PJ. Treatment of severe falciparum malaria during pregnancy with quinidine and exchange transfusion. Am J Med 1992;92:561-562.

25. Tejura B, Sass DA, Fischer RA, Daskal I, Eiger G. Transfusionassociated falciparum malaria successfully treated with red blood cell exchange transfusion. Am J Med Sci 2000;320: 337341.

26. Kendrick BJ, Gray AG, Pickworth A, Watters MP. Drotrecogin alfa (activated) in severe falciparum malaria. Anaesthesia 2006;61:899-902.

27. Nielsen RL, Kohler RB, Chin W, McCarthy LJ, Luft FC. The use of exchange transfusions: a potentially useful adjunct in the treatment of fulminant falciparum malaria. Am J Med Sci. 1979;277:325-329.

28. Roncoroni AJ, Martino OA. Therapeutic use of exchange transfusion in malaria. Am J Trop Med Hyg 1979;28:440-444.

29. Kumar S, Kothari S, Karnad DR. Predicting the reduction of parasitaemia following exchange transfusion in severe Plasmodium falciparum malaria: comparison of two mathematical formulae. Ann Trop Med Parasitol 2003;97:489-4.92.

30. Lataste P, Soubiran G, Nlend A, Le Bras M, Roue R, Wone C, Ragnaud JC, Buil A, Briand MC, Ripert C, et al. [Value of exchange transfusion in the treatment of severe malaria (apropos of 5 cases)]. Bull Soc Pathol Exot Filiales. 1987;80(3 Pt 2):561-568.

31. Macallan DC, Pocock M, Bishop E, Bevan DH, Parker-Williams J, Harrison T, Robinson GT. Automated erythrocytapheresis in the treatment of severe falciparum malaria. J Infect 1999;39:233-236.

32. Gulprasutdilog S, Chongkolwatana V, Buranakitjaroen P, Jaroonvesama N. Exchange transfusion in severe falciparum malaria. J Med Assoc Thai 1999;82:1-8.

33. Reichard U, Möller H, Eiffert H, Ramadori G, Schwörer H. [Successful management of malaria tropica with 50\% parasitaemia]. Dtsch Med Wochenschr. 2006;131:2010-2012.

34. Canada Communicable Disease Report 2011: table 1 (http:// www.phac-aspc.gc.ca/publicat/ccdr-rmtc/11vol37/acs-3/ index-eng.php) 